\title{
TU/e emonownen

\section{Level-set method used to track the glass-air interface in the blow step of glass containers}

Citation for published version (APA):

Giannopapa, C. G., \& Groot, J. A. W. M. (2007). Level-set method used to track the glass-air interface in the blow step of glass containers. (CASA-report; Vol. 0709). Technische Universiteit Eindhoven.

Document status and date:

Published: 01/01/2007

\section{Document Version:}

Publisher's PDF, also known as Version of Record (includes final page, issue and volume numbers)

\section{Please check the document version of this publication:}

- A submitted manuscript is the version of the article upon submission and before peer-review. There can be important differences between the submitted version and the official published version of record. People interested in the research are advised to contact the author for the final version of the publication, or visit the $\mathrm{DOI}$ to the publisher's website.

- The final author version and the galley proof are versions of the publication after peer review.

- The final published version features the final layout of the paper including the volume, issue and page numbers.

Link to publication

\section{General rights}

Copyright and moral rights for the publications made accessible in the public portal are retained by the authors and/or other copyright owners and it is a condition of accessing publications that users recognise and abide by the legal requirements associated with these rights.

- Users may download and print one copy of any publication from the public portal for the purpose of private study or research.

- You may not further distribute the material or use it for any profit-making activity or commercial gain

- You may freely distribute the URL identifying the publication in the public portal.

If the publication is distributed under the terms of Article 25fa of the Dutch Copyright Act, indicated by the "Taverne" license above, please follow below link for the End User Agreement:

www.tue.nl/taverne

Take down policy

If you believe that this document breaches copyright please contact us at:

openaccess@tue.nl

providing details and we will investigate your claim. 


\title{
Level-set method used to track the glass-air interface in the blow step of glass containers
}

\author{
C. G. Giannopapa and J.A.W.M.Groot \\ Dept. of Mathematics and Computer Science \\ Technische Universiteit Eindhoven \\ PO Box 513, 5600 MB Eindhoven \\ The Netherlands
}

\begin{abstract}
An application of the level-set method in a finite element library for the simulation of the glass forming process is described. The forming process of containers (i.e bottles, jars) results in a thermomechanical problem with an evolving glass air interface posing a great challenge in modeling. The finite element method is used in our computations to accurately simulate the glass flow, the process' energy exchange with the heavily temperature dependent viscosity of the glass. Our model uses the level set method to track the glass-air interface. In this way remeshing can be avoided and computational costs can be significantly reduced. The glass-air interface can be seen as two interfaces: inner glass air interface and an outer glass-air interface. Thus, we solve two level set equations which allow us to apply the correct material parameters to the aforementioned equations without explicitly having to trace the glass surfaces. Numerical examples are provided tracking the glass-air interface of the blowing of a preform with non-uniform temperature.
\end{abstract}

Keywords: glass forming, thermomechanical problems, nonlinear viscoelasticity, level set

\section{INTRODUCTION}

Manufacturing of glass containers such as bottles and jars gathers years of hands-on experience. Most of the glass manufacturing is carried out in closed constructions involving high temperatures. It is difficult to measure and control in those temperature. Over the last twenty years numerical methods used for modeling various aspects of the production have become of great importance in understanding, controlling and optimizing the process $[1,2]$.

During the manufacturing of containers the molten glass is cut in gobs and arrives in the forming machinery. There the final shape of the container is given in two steps, either by blow-blow or by pressblow (Figure 1). Considering the press-blow case, the gob arrives at the first mould called the press mould and it is pressed by a plunger to a preform shape (Figure 1a). This preform is then transferred to a second mould the blow mould. There it is left to sag from gravity and then with pressurized air is forced to take the shape of the mould.

The modeling of glass forming gives rise to complex physical aspects involving continuum mechanics, heat transfer and free surface flows. Small changes in the glass composition, preform and mould temperature can result in significant changes in the final product.

In this paper we are concerned with modeling of the second blowing step of the forming process. As the glass flows towards the mould the glass-air interface changes position constantly during this process. There are various numerical techniques that can be used to model the evolution of this free surface and can be mainly classified into: interface tracking techniques and interface capturing techniques.

In interface tracking techniques the moving interface is represented and tracked explicitly either by marking it with special marker points, or by attaching it to a mesh surface. In [3] a mesh updating technique is used, applied in blowing glass containers.

In interface capturing techniques the interface is simulated either by using massless particles or an indicator function that marks the two fluids on either side of the interface. This method is based on an Eulerian approach and works on a fixed mesh. Once the mesh is generated it is used for the entire computation without any updates. Thus, complex geometries can be computed without additional computational costs related to mesh update. The two most widely used methods in this category are the 
volume of fluid method (VOF) [4] and the level set method $[6,7]$.

In the volume of fluid method the interface is represented implicitly by a color function, defined to be the fraction of volume of one of the two fluids within each cell. The reconstruction of the interface can be made from this function. The interface is propagated implicitly by updating this color function. The VOF methods are robust, but as they do not explicitly represent the interface in many cases appropriate boundary conditions can not be prescribed with required accuracy. The method is only first order accurate [5].

The level set method is based on the idea of representing the common interface by the zero contour of a signed distance function the level set function. To keep the level set function as a distance function, a reinitialisation process is needed. The main advantage of the level set function is that it can deal automatically with topological changes such as sharp corners, spitting and merging. This method can obtain high order accuracy. One of the drawbacks of this method is that it is not conservative, it may exhibit mass gain or loss, which is physically incorrect. Several attempts have been described in the literature to improve this [17]

The objective of this paper is to implement a level set technique to model the blow step of the forming process of glass containers. The model should be able to accurately describe the glass-air interface evolution during the highly temperature dependent flow. The model should be able to assist optimization of industrial design of glass containers. It should be able to use preforms obtained by the first forming step (press or blow) and obtain the final product providing information regarding the final shape, thickness and temperature distribution.

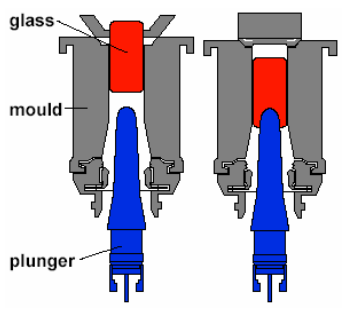

(1a)

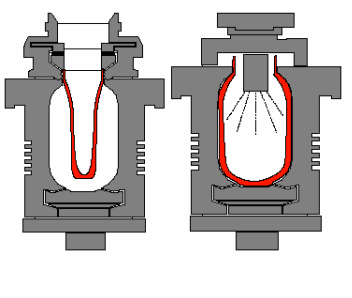

(1b)
FIGURE 1. Glass forming by press-blow process

\section{PROBLEM FORMULATION}

A blow mould to produce bottles with dimensions: top radios of $0.0127 \mathrm{~m}$, bottom radius of $0.0265 \mathrm{~m}$ and height of $0.21 \mathrm{~m}$ is considered with a preform hanging inside. The glass blowing evolves the flow of glass and air, the heat transfer during the process and the evolution of the glass-air interface.

\section{Fluid Flow}

The glass can be modeled as an incompressible fluid [8]. We assume that the air can flow freely out of the mould and we model it as an incompressible fluid.

Incompressible fluid flow problems with small Reynolds numbers where viscous forces dominate can be described by the Stokes equation and the divergence-free condition.

$-\nabla p+\mu \nabla^{2} \mathbf{U}+\rho \mathbf{b}=0$

$\nabla \cdot \mathbf{U}=0$

where $\mathbf{U}$ is the fluid velocity, $\mu$ is the fluid viscosity, $p$ is the pressure and $\mathbf{b}$ is the body force. The material properties used can be seen in Table 1. In the case concerned the Reynolds number for the glass is $2.53 \cdot 10^{-5}$ and for the fictitious fluid representing the air it is $4.76 \cdot 10^{-5}$, so the stokes flow equation can be used for the description of the flow.

\section{Heat Transfer}

The energy exchange between the glass, air and the equipment can be described by the energy equation for an incompressible fluid in an Eulerian framework as:

$\rho c_{p}\left(\frac{\partial T}{\partial t}+\mathbf{U} \cdot \nabla T\right)=-\nabla \cdot \mathbf{q}$

where $c_{p}$ is the specific heat of the glass, $q$ is the heat flux and $\phi$ is the source term from the internal heat generation by viscous and volume forces. Neglecting the heat transfer due to radiation and assuming that the conduction obeys the Fourier law which relates the heat flux vector to the temperature $\mathrm{T}$ by thermal conductivity $\mathrm{k}$ as:

$\mathbf{q}=-k \nabla T$

Thus, the energy equation can be written as:

$\rho c_{p}\left(\frac{\partial T}{\partial t}+\mathbf{U} \cdot \nabla T\right)=k \nabla^{2} T$

The preform typically has a non-uniform distribution of temperature when it comes from the first blow mold. In order to simulate that the temperature was varied by: 
$T(x, y)=T_{0}\left(1-\lambda_{y} e^{-k_{y} y}\right)+\sum_{k=1}^{4}(-1)^{k}\left(T_{k, x} x^{k}+T_{k, y} y^{k}\right)$

where the parameters used can be found in Table 2 .

The viscosity of the glass strongly depends on temperature according to the Vogel-Fulcher-Tammann (VFT) relation [1]:

$\eta(T)=10^{A+B /\left(T-T_{L}\right)}$

where $\mathrm{A}=-2.76 \log (\mathrm{Pa} \cdot \mathrm{s}), \mathrm{B}=5690 \quad{ }^{\circ} \mathrm{C} \cdot \log (\mathrm{Pa} \cdot \mathrm{s})$, $\mathrm{T}_{\mathrm{L}}=189{ }^{\circ} \mathrm{C}$ are the Lakatos coefficients. The change of the viscosity strongly influences the thickness of the final product. Figure 1 presents how the viscosity varies with the temperature in the preform used in this paper.

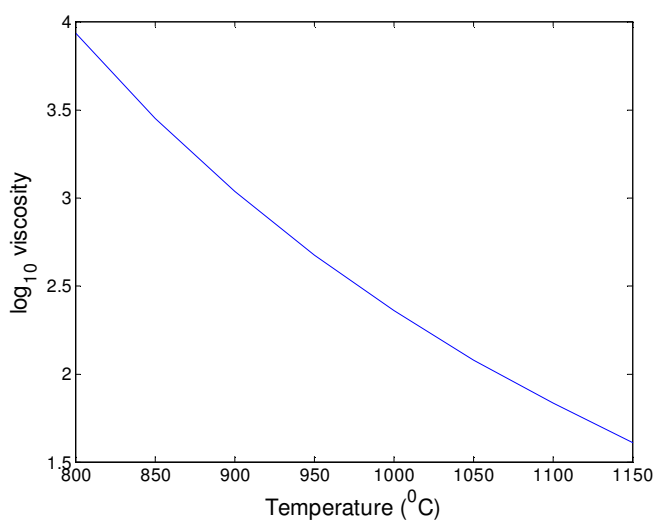

FIGURE 2. Viscosity-temperature curve.

\section{Interface Tracking}

The glass-air interface is represented using the level set method. The basic idea is to embed a moving interface as the zero level set of the interface function $\phi$, which serves as a marker identifying the interface between glass and air. The evolution of the zero level set, thus the motion of the interface, is governed by the convention equation:

$$
\frac{\partial \phi}{\partial t}+\mathbf{U} \cdot \nabla \phi=0
$$

So, at any time $\mathrm{t}$ the corresponding interface is given implicitly by $\phi(x, t)=0$. In this project, for the position of the glass-air interface two level sets are used, one describing the inner interface of the preform and the other the outer one (Figure 3).

The level set function $\phi$ is initially an Eucledian distance function to the corresponding interface where $\|\nabla \phi(\mathbf{x}, 0)\|=1$.

One of the difficulties in tracking the interface using level sets is that after a while the gradient of $\phi$ is not equal to one. This results in the increase or decrease of mass. In order to correct this a reinitialization technique may be used. The first reinitialisation technique was introduced in [9].

The reinitialisation technique implemented and use in this paper is based on the idea of fast marching methods $[7,10,11]$. The surface is propagating outward with a velocity in an unwinding fashion. The interface is carried along the computational domain by a narrow band around it and marching along the grid points.

The fast marching methods solve the following boundary value equation in the computational domain:

$\|\nabla d(\mathbf{x})\|_{2}=1$,

on the interface for the distance function d holds:

$d(x)=0$

The surface tension acting on the interfacial surface is neglected in our calculations. In the case were level sets are used for the propagation of the free surface the surface tension may be included as a body force in the momentum equation [12].

\section{Boundary Conditions}

The schematic of the boundary description of the domain concerned shown in Figure 3 with $\Gamma_{\mathrm{i}}$ being the inlet boundary, $\Gamma_{\mathrm{s}}$ the symmetry plane and $\Gamma_{\mathrm{m}}$ representing the mould. The inflow pressure is $\mathrm{p}_{\mathrm{i}}=1.38 \cdot 10^{5} \mathrm{~Pa}$, the temperature of the air is $\mathrm{T}_{\mathrm{a}}=600{ }^{\circ} \mathrm{C}$ and the temperature of the mould is $\mathrm{T}_{\mathrm{m}}=550{ }^{\circ} \mathrm{C}$. For the solution of the flow problem in the mould domain a free slip boundary condition is assumed for the air and a no slip boundary condition is assumed for the glass.

\begin{tabular}{|l|l|l|}
\hline air density & $\rho_{a}\left[\mathrm{~kg} \mathrm{~m}^{-3}\right]$ & 1 \\
\hline glass density & $\rho_{g}\left[\mathrm{~kg} \mathrm{~m}^{-3}\right]$ & 2530 \\
\hline air (fictive) viscosity & $\mu_{a}[\mathrm{~Pa} \mathrm{~s}]$ & 2.1 \\
\hline air specific heat & $c_{p, a}\left[\mathrm{~J} \mathrm{Kg}^{-1} \mathrm{~K}^{-1}\right]$ & 1000 \\
\hline glass specific heat & $c_{p, g}\left[\mathrm{~J} \mathrm{Kg}^{-1} \mathrm{~K}^{-1}\right]$ & 1400 \\
\hline air effective conductivity & $\lambda_{a}\left[\mathrm{Wm}^{-1} \mathrm{~K}^{-1}\right]$ & 0.03 \\
\hline glass effective conductivity & $\lambda_{b}\left[\mathrm{Wm}^{-1} \mathrm{~K}^{-1}\right]$ & 0.03 \\
\hline
\end{tabular}

TABLE 1. Parameters for glass and air. 


\begin{tabular}{|l|l|}
\hline$T_{0}=3.2104 \cdot 10^{3}$ & $T_{2, y}=4.3 .0587 \cdot 10^{5}$ \\
\hline$T_{1, x}=6.9036 \cdot 10^{4}$ & $T_{3, y}=6.9616 \cdot 10^{5}$ \\
\hline$T_{2, x}=1.7209 \cdot 10^{7}$ & $T_{4, y}=0.0$ \\
\hline$T_{3, x}=1.3748 \cdot 10^{9}$ & $\lambda_{y}=3.3887 \cdot 10^{5}$ \\
\hline$T_{4, x}=3.2284 \cdot 10^{10}$ & $\kappa_{y}=200$ \\
\hline$T_{1, y}=4.4453 \cdot 10^{4}$ & \\
\hline
\end{tabular}

TABLE 2. Parameters for non-uniform temperature distribution of the preform.

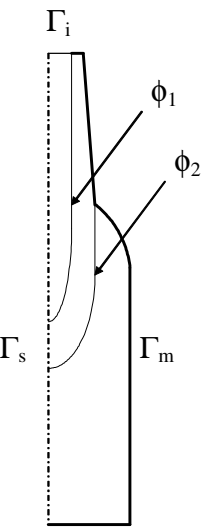

FIGURE 3. Boundary settings and interface representation.

\section{FINITE ELEMENT DISCRETISATION}

The numerical simulation of the glass forming was performed using finite element method for the solution of the Stokes problem, the heat problem and the levelset evolution of the two glass air interfaces. These were implemented in the SEPRAN finite element package.

A typical mesh descriptions for structured mesh can be seen in Figure 4. The mini element is used for the computations [13].

The resulting equations for the Stokes problem are solved using the BI-CGSTAB method [14]. This iteration method terminates after a finite number of iteration steps. As a stepping criterion the absolute value of the residual is less than $10^{-8}$. As an initial guess for the iteration process the solution obtained in the previous time step is used.
The stabilized formulation of the energy equation is obtained using the streamline-upwind PetrovGalerkin (SUPG) method $[15,16]$. The BI-CGSTAB method [14] is used to solve of the equations up to an accuracy of $10^{-6}$. As before, the values obtained from the previous time step are used as an initial guess. For the level set solution the accuracy used is $10^{-8}$. For the time discretisation the Euler Implicit scheme was used for a the solution of flow energy and level set problems.

\section{NUMERICAL EXAMPLES}

The examples tested refer to commercial bottle containers. The information regarding the geometry of the mould and manufacturing conditions were supplied by manufacturers.

The preform shape used in these numerical examples has been obtained by the first stage of the forming process which has not been explicitly modeled. Its shape can be seen in Figure 5(a).

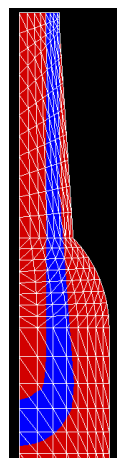

FIGURE 4. Typical mesh representation.

In the computations a mesh of 6720 elements and 3525 points was used. A typical representation of the mesh can be seen in Figure 4. In the numerical examples tested it is assumed that the preform is initially stretched by gravity followed by the forming of the final product by brevity and internal pressure imposed at the top of the preform.

The temperature distribution of the preform is described by Equation (6) and the temperature contours can be seen in Figure 6(a). The initial temperature distribution of the preform was given by a manufacturer.

The preform was stretched first by gravity for 0.5 seconds and then was blown against the mould with a pressure of $1.38 \cdot 10^{5} \mathrm{~Pa}$. The stretch of the preform and its temperature profile can be seen in Figure 5 (b) and 6(b) respectively. In Figure 5 (c) and 6(c) intermediate 
situations of the location of the glass in the mould and its temperature profiles are shown. The final shape of the bottle and the temperature at the end of the blowing process can be seen in Figures 5 (d) and 6(d). The thickness of the final product can be seen in Figure 7.

Since level set method is not always conservative the mass conservation of glass was used to check the accuracy of the simulations. The fast marching method has been used as a reinitialisation technique during the computations for both the stretch and the blow simulation and the volume of glass over the initial glass volume can be seen in Figure 8 . As it can be seen there is a small increase of volume which results to maximum of $2 \%$ increase of volume. This can be further improved by using the Crank Nicholson method for the time integration which is second order accurate rather than the Euler implicit which is fist order accurate. This would result though in an increase of the computational time.
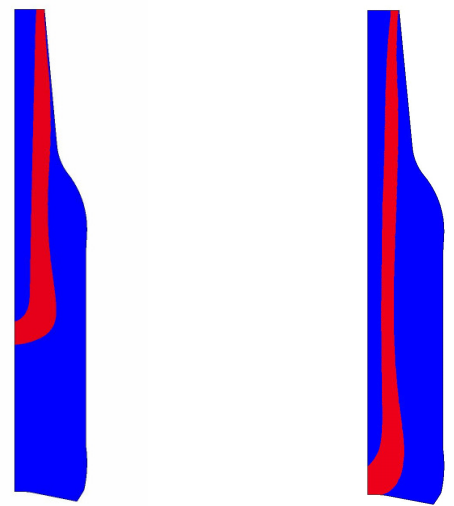

(a) $\mathrm{t}=0.0$

(b) $\mathrm{t}=0.5$
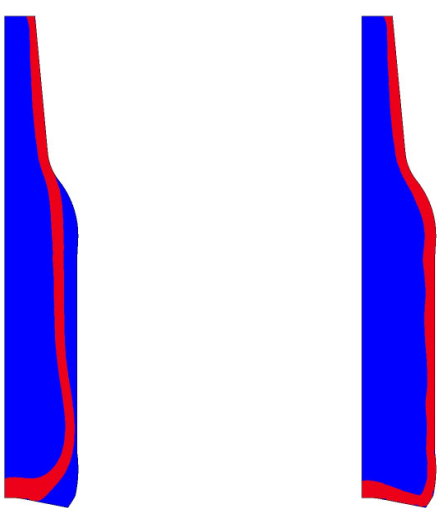

(c) $\mathrm{t}=0.88$

(d) $\mathrm{t}=1.17$

FIGURE 5. Glass position (red) for (a) initial $t=0$, (b) after stretching $\mathrm{t}=0.5$, (c) during blow $\mathrm{t}=0.88$ and (d) end of blow $\mathrm{t}=1.17$.

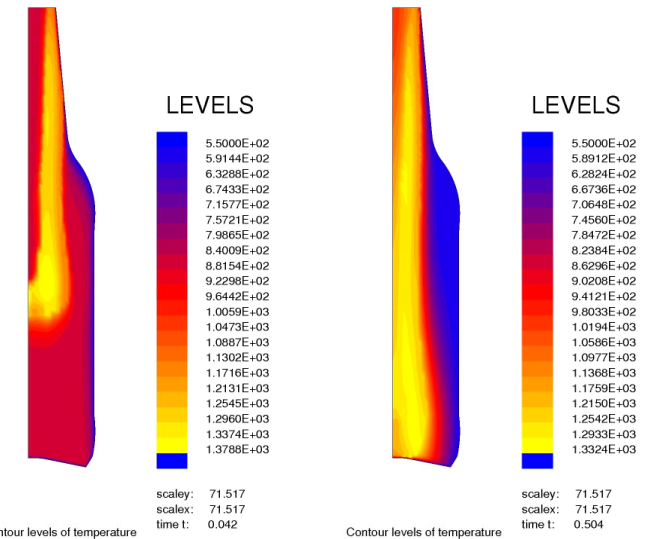

(a)

(b)

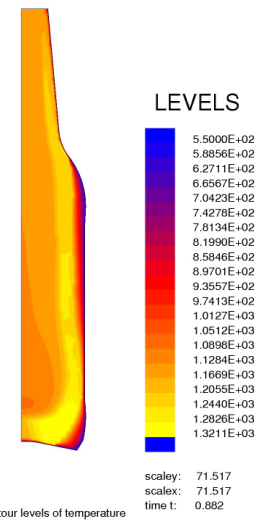

(c)

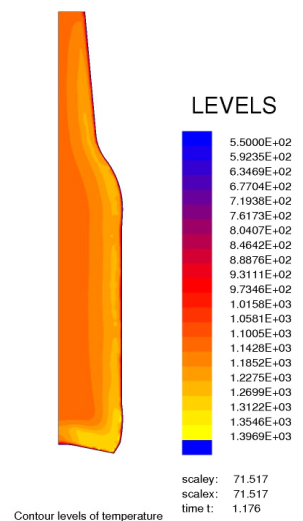

(d)

FIGURE 6. Temperature contour levels: (a) initial and (b) after stretching, (c) during blow (d) at the end of blow.
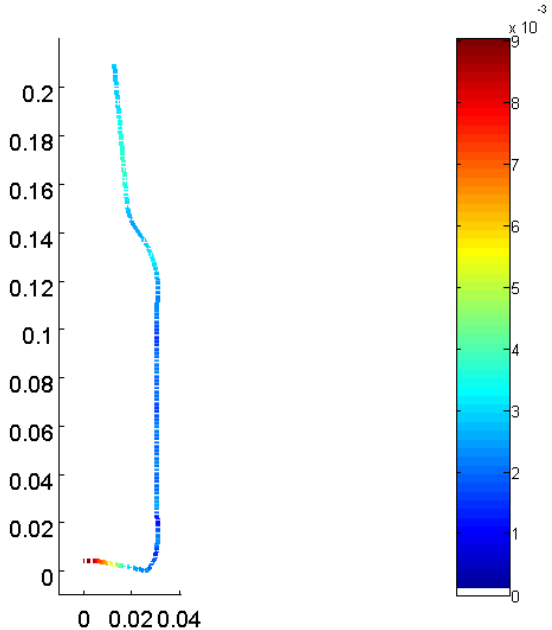

FIGURE 7. Thickness distribution of final product [m]. 


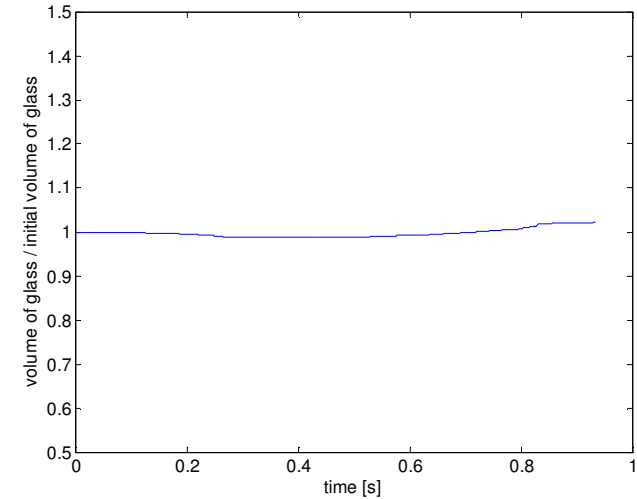

FIGURE 8. Volume conservation for stretching and blowing using Euler Implicit scheme with time step $\Delta \mathrm{t}=1 \mathrm{e}-4$.

\section{CONCLUSIONS}

The numerical model presented in this paper demonstrates the use of a level set method with reinitialisation for the simulation of the second step namely the blowing step of the forming process of glass containers. This technique is based on using a single fixed mesh for the computations which decreases additional computational time related to mesh updates.

This method provides information regarding the temperature distribution of the glass and the air as well as the thickness of the final product.

Further studies should be performed to assess the numerical sensitivity of the model. The influence of physical parameters of the process with regards to the thickness of the final product should also be further investigated.

\section{REFERENCES}

1. F. V. Tooley, The handbook of glass manufacture, New York: Aslee Publishing Co, 1984, Vol II.

2. H. Loch and D. Krause, Mathematical simulation in glass technology, Berlin and Heidelberg: SpringerVerlag, 2002.

3. Cesar de Sa, J. M. A., Eng. Comput., , Vol. 3, 266-275 (1986).

4. Hirt, C. W., and Nichols, B. D., J. Comput. Phys. 39, 201-225 (1981).

5. Rider, W. J., and Koth, D. B., Comput. Phys.141, 112152 (1998).

6. Osher, S. A., and Sethian, J. A., J. Comput. Phys. 79(1), 12 (1994).

7. Sethian, J. A., Level Set Methods and Fast Marching Methods, USA: Cambridge university press, 1999.

8. Sawai, I., and Inoue, S., Journal of the Society of Chemical Industry of Japan, Transactions 43(2), 47B49B (1940).

9. Sussman, M., Smereka, P. and Osher, S., J. Comput. Phys. 114, 146 (1994)

10. Sethian, J. A., Proc. Nat. Acad. Sci., 93, 1591-1595 (1996).

11. Chopp, D. L., SIAM. Journal of Scientific Computing, 23(1), 230-244 (2001).

12. Shepel, S. V., and Smith, B. L., Transaction of the ASME 127, 674-689 (2005)

13. Bathe, K.J., Finite element procedures, edited by New Jersey: Prentice Hall, Englewood Cliffs, 1997.

14. van der Vorst, H. A. SIAM. J. Sci Stat. Comput., 13(2), 631-644 (1992).

15. Brooks, A. N., and Hughes, T.J.R., Comput. Methods Appl. Mech. Eng., 32, 199-259 (1982).

16. Jonson, C., and Nävert, U. and Pitkäranta, J., Compt. Methods Appl. Mech. Eng. 45, 285-312 (1984).

17. Olsson, E., and Kreiss, G., J. Comp. Physics 210, 225 246 (2005)

\section{ACKNOWLEDGMENTS}

The Authors would like to thank the MAGICAL Marie Currie Research Training Networks Fellowships, European Commission and the Eindhoven University of Technology student assistantships for funding this project. 